\section{A BOOST FOR DENTAL EDUCATION IN BILLINGHAM}

Queensway Dental Clinic in Billingham has officially opened a new Education Centre. Housed in its own building close to the practice, the centre can accommodate 30 delegates and is equipped to cater for a diverse range of courses and lectures.

The creation of the centre is in direct response to an increased demand for a regional training facility which corresponded with Queensway's plans to enhance its event programme, training days and postgraduate offerings.

Paul Averley, Partner at Queensway Dental Clinic said: 'Not only is the new centre a great investment and resource for the dental industry, it also reinforces our commitment to the ongoing regeneration of Billingham and the growth of the business community in the town.'

The practice will work closely with several industry experts, including Warwick University and Nobel Biocare, and is certified to deliver the National Accreditation Board for Dental Nurses (NEBDN) qualifications for dental sedation nursing, dental radiography and oral health education.

A Queensway lecture series will be launched later in the year and further training events will be announced on the clinic's website, www.queensway.co.uk.

\title{
WAS MARY POPPINS RIGHT?
}

An opinion article published in this issue of the $B D J$ (pages 207-208) says that administering sugar-free medicine to a child consuming lots of sweets is futile.

Moreover, author Dr Santhanam Sundar says that there is no robust evidence that the small amount of sugar in medicines has been responsible for any dental problems, and the sugar makes them palatable and therefore influences compliance with treatment.
'Poor compliance leads to inadequate treatment of illness and consequently increases the risk of complications,' says Dr Sundar. 'Hence sugar-free medicines promoted as a public health policy could have actually caused more harm than any meaningful net benefit.'

The article calls urgently for a 'healthy debate and a fresh look at the policy of promoting sugarfree medicines'.

\section{COMPUTER-GUIDED IMPLANT SUCCESS}

A case study says that innovative modifications of software and instrumentation are further advancing dental implant success in patients lacking adequate bone. ${ }^{1}$

It reports the use of computerguided implantation in a 54-yearold who had a very narrow ridge of bone, making drilling for implant placement difficult.

Previously, this clinical situation required opening a flap and reducing bone before placing the implants. In the virtual planning phase of this case study, a different implant length was used to reposition the guide sleeves. Drilling sequences were changed, using a starting drill that would allow deeper penetration. Osteotomes and an alternative implant seating mount were incorporated. A successful computer-guided implant was accomplished.

1. Schnitman PA, Lee S J, Campard G J, Dona M. Guided flapless surgery with immediate loading for the high narrow ridge without grafting. J Oral Implantol 2012; 38: 279-288.

\section{BDA HONOURS AND AWARDS 2012}

\section{BDA Fellowship}

Dr Mike Arthur, general dental practitioner and former Chair of the BDA's Scottish Council

Dr Lester Ellman, general dental practitioner and former Chair of the BDA's General Dental Practice Committee Dr Raj Joshi, consultant in restorative dentistry, former Chairman and President of the South Yorkshire Branch

\section{BDA Life Membership}

Dr John Mooney, current Chair and former President of the BDA's East Lancashire Cheshire Branch

Mr Jackie Morrison who has served both the BDA's

Community Dental Services Group and its West of Scotland Branch in roles including President

Dr Richard Ward, former Chair of the BDA's Central Committee for Community Dental Services (now Salaried Dentists Committee)

\section{BDA Roll of Distinction}

Tony Reed, BDTA Executive Director Emeritus Professor Phillip Sutcliffe Linda Wallace, BDA Director

BDA's Certificate of Merit for Services to the Association Dr Malcolm Heath

Dr John Herrick

BDA's Certificate of Merit for Services to the Profession Dr David Croser

Dr Mervyn Druian

\section{DO YOU KNOW AN UNSUNG HERO?}

As part of Colgate Oral Health Month, taking place all through September, Colgate has launched a search to find the dental profession's greatest unsung hero.

Colgate is inviting anyone working in a dental practice who has pioneered an innovative and effective way of communicating the oral health message to children, dedicated their energies to transforming the

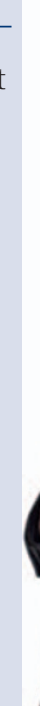

